\title{
The influence of late onset hypogonadism on the formation of proinflammatory cytokines imbalance in patients with obesity and type 2 diabetes.
}

\author{
Irina Khripun, Zalina Gusova, Elizaveta Dzantieva, Valentina Puzireva, Asiat Sultanmuradova, Sergey Vorobiev \\ Rostov State Medical University, Rostov-on-Don, Russia
}

\section{Background:}

\section{Objectives:}

\section{Methods:}

\begin{abstract}
Currently actively studied the role of certain inflammatory and proinflammatory cytokines in the pathogenesis of insulin resistance, type 2 diabetes, obesity, atherosclerosis. However, the influence of testosterone deficiency on the balance of proinflammatory cytokines is unexplored.
\end{abstract}

The aim of the work was to evaluate the influence of testosterone deficiency on metabolic parameters and levels of proinflammatory cytokines in patients with obesity and type 2 diabetes.

We examined 85 male patients, aged 40-65 years with obesity and type 2 diabetes. Clinical examination included the measurement of body weight, height, hip and waist circumferences and blood pressure. A sample of fasting venous blood was taken to measure $\mathrm{HbA1c}$, lipid profile, total testosteron, TNF- $\alpha$ and IL-6.

All patients were devided into 2 groups, matched for age, according the level of testosterone. The first group included 44 patients with testosterone levels above $12.1 \mathrm{nM} / \mathrm{L}$, the second -41 men with content of hormone less than $12,1 \mathrm{nM} / \mathrm{L}$.

Table 1. The content of metabolic parameters and proinflammatory cytokines according to the level of testosterone

\begin{tabular}{|c|c|c|c|}
\hline Parameter & $\begin{array}{c}\text { Group 1 } \\
\mathrm{n}=44\end{array}$ & $\begin{array}{c}\text { Group 2 } \\
\mathrm{n}=41\end{array}$ & $\mathrm{P}$ \\
\hline $\mathrm{IMC}, \mathrm{kg} / \mathrm{m}^{2}$ & $34,36 \pm 1,22$ & $42,03 \pm 1,44^{*}$ & 0,032 \\
\hline $\mathrm{HBA1C}, \%$ & $6,17 \pm 0,16$ & $7,55 \pm 0,22^{*}$ & 0,043 \\
\hline $\mathrm{CT}, \mathrm{mol} / \mathrm{l}$ & $5,79 \pm 0,16$ & $6,64 \pm 0,13^{*}$ & 0,047 \\
\hline $\mathrm{TG}, \mathrm{mol} / \mathrm{l}$ & $1,72 \pm 0,17$ & $2,31 \pm 0,31^{*}$ & 0,049 \\
\hline $\mathrm{TNFa}, \mathrm{pg} / \mathrm{ml}$ & $4,38 \pm 0,37$ & $6,32 \pm 0,49^{*}$ & 0,036 \\
\hline $\mathrm{IL}-6, \mathrm{pg} / \mathrm{ml}$ & $3,78 \pm 0,36$ & $5,39 \pm 0,89^{*}$ & 0,029 \\
\hline
\end{tabular}

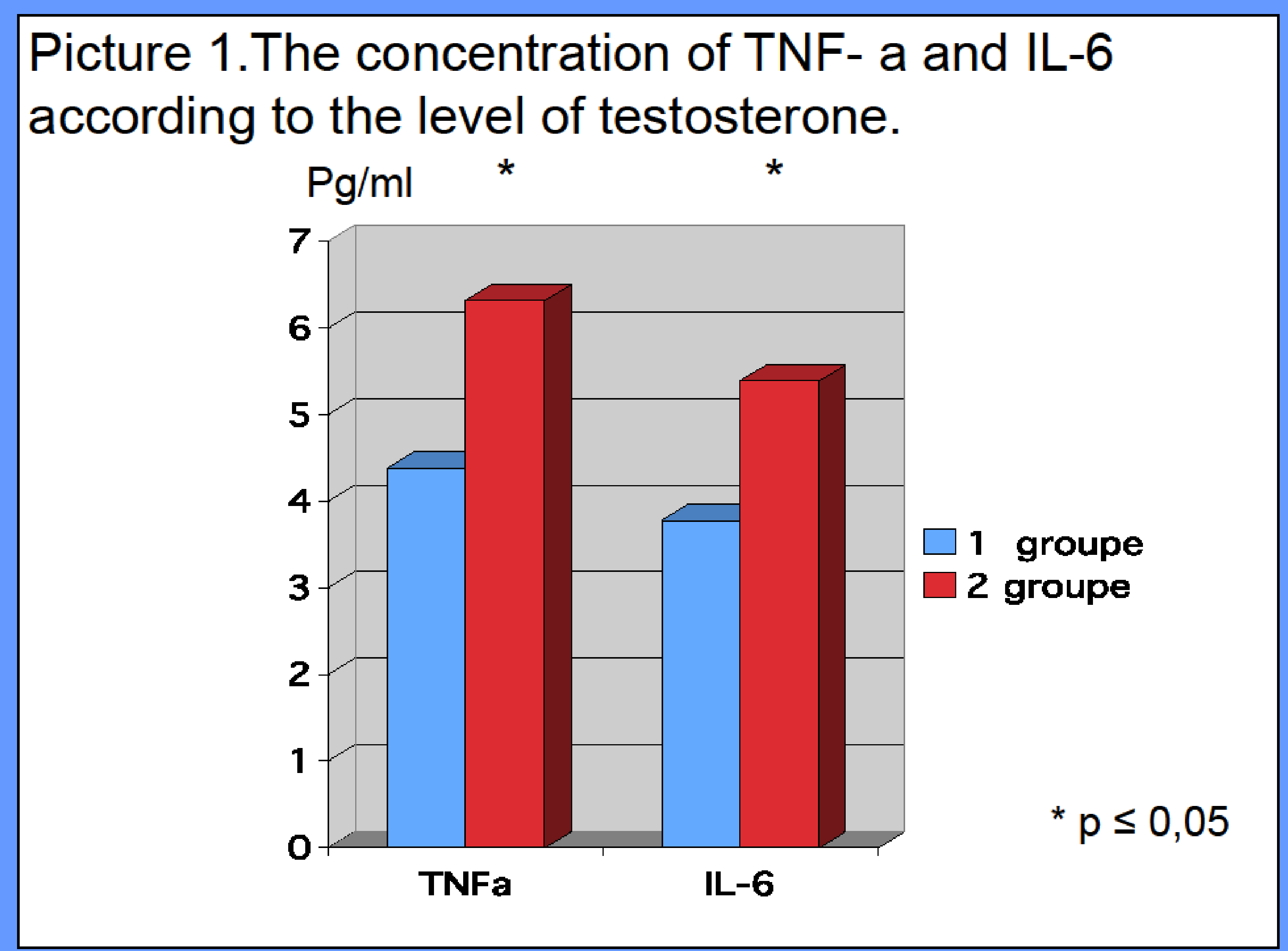

\section{Results:}

Among the studied patients, 58\% men had atherogenic dyslipidemia, manifesting as an increase in the content of TC, LDL, TG and atherogenic index. $62 \%$ of patients had arterial hypertension.

Analysis of the data shows a statistically more significant body mass index (BMI) in the group of hypogonadal patients (BMI 42,03 $\pm 1,44 \mathrm{~kg} / \mathrm{m}^{2}$ ), compared with eugonadal males (BMI $34,36 \pm 1,22 \mathrm{~kg} / \mathrm{m}^{2}$ ). In the second group there were a statistically significant increases in the levels of $\mathrm{HbA} 1 \mathrm{c}(7,55 \pm 0,22 \mathrm{vs} 6,17 \pm 0,16 \%)$, serum TC $(6,64 \pm 0,13$ vs $5,79 \pm 0,16 \mathrm{mM} / \mathrm{l})$ and TG $(2,31 \pm 0,31$ vs $1,72 \pm 0,17 \mathrm{mM} / \mathrm{l})$.

In estimating the concentration of TNF-a in the serum was found that its level in patients with deficiency of testosterone $(6,32 \pm 0,49 \mathrm{pg} / \mathrm{ml})$ was significantly higher $(p \leq 0.05)$ that those without hypogonadism $(438 \pm 0,37$ $\mathrm{pg} / \mathrm{ml}$ ). The results of the study of IL- 6 showed a statistically significant increase in its content in the serum of patients with late onset hypogonadism $(5,39 \pm 0,89 \mathrm{pg} / \mathrm{ml})$ compared with eugonadal patients $(3,78 \pm 0,36 \mathrm{pg} / \mathrm{ml})$.

Our study shows the deterioration of control of carbohydrate and lipid metabolisms in males with type 2 diabetes mellitus and late onset hypogonadism. Also the hypotestosteronemy was contributed to the activation of pro-inflammatory cytokines TNF- $\alpha$ and IL-6, which could reinforce the severity of metabolic desoders and progressing of cardiovascular pathology.

Thus, reduced serum testosterone level is a factor, contributing to manifestation of metabolic disorders and cytokine imbalance in patients with obesity and type 2 diabetes. Androgen deficiency may be regarded as an additional risk factor for cardiovascular disease and diabetes. 